\title{
STUDY ON LIQUID MOISTURE TRANSPORT OF KNITTED FABRICS BY MEANS OF MMT, THERMOGRAPHY AND MICROTOMOGRAPHY SYSTEMS
}

\author{
Renata Nemcokova, Viera Glombikova*, Petra Komarkova \\ Technical University of Liberec, Faculty of Textile Engineering, Department of Clothing Technology, \\ Liberec, Czech Republic, Studentska 1402/2, 461 17, Liberec, tel. +420 485353 124, fax. +420 485353204 , \\ *corresponding author e-mail: viera.glombikova@tul.cz
}

\begin{abstract}
:
Liquid moisture transport of textile structures has been studied in order to manage human perspiration well. This article deals with investigation of dynamic moisture transport of knitted fabrics by sophisticated methods, such as moisture management tester (MMT), thermography and microtomography systems. Three groups of knitted fabrics were analysed by the above-mentioned methods. Specifically, the distribution of liquid drops on samples was compared with the results of vertical wicking of tested materials and the parameter of three-dimensional fabric porosity. Both dynamic spreading of liquid drops on the surface of samples (from top and bottom sides simultaneously) and vertical wicking behaviour of textiles were analysed by the combination of thermography and image analysis system. Further, the results from MMT and porosity analysis by microtomography system were investigated to specify the interaction between structure parameters of knitted fabrics and their liquid transport properties which influence total wear comfort.
\end{abstract}

\section{Keywords:}

liquid moisture transport, wicking behaviour, MMT, microtomography, thermography, 3D porosity

\section{Introduction}

Comfort is the key element to be respected in clothing design and production. Apart from thermal properties of fabrics that primarily provide thermal balance of the human body, moisture transport properties are significant to safe total physiological comfort of a wearer. Larger amount of sweat and higher body temperature are the outcome of intense activities such as sports and exercises or higher ambient air temperature. If the heat and moisture are not released effectively from the body, heat stress may occur and the wearer's performance will be negatively affected [4]. If garment cannot transport sweat in a vapour form away from the skin sufficiently and quickly enough, sweat condenses on the skin or inner fabric surface. The amount of sweat absorbed by clothes is influenced by the thermal and sorption properties of knitted clothes, as well as by the openness of clothing [8].

The undergarment should transport this liquid moisture away from the skin or inner fabric surface to the outer surface as soon as possible to ensure a safe level of comfort for users. Therefore, dynamic liquid moisture transport is very important to reduce the humidity on the surface of the skin [2]. Moisture management of fabrics is mainly influenced by the fibre type, yarn construction and fabric construction $[17,20]$. The density and structure of yarns can greatly influence both the dimensions and structure of inter- and intrayarn pores. The pore size and their distribution are determined by the manner in which fibres are assembled into the woven, nonwoven, or knitted structures too [5].
Recent research has even proved that the loosely knitted fabric samples with a higher amount of entrapped air exhibit good air permeability but poor moisture management properties [17]. The flow of liquid in fibre assemblies, such as yarn and fabric, mainly happens due to capillary forces [11]. This capillary force depends on the radius of the capillary channel and the contact angle between liquid and capillary channel as well as rheological properties of the liquid [1].

Wicking methods belong to well-known methods that use the capillary phenomenon to evaluate liquid transport properties of fabrics. In general, wicking takes place when a liquid travels along the surface of the fibre but is not absorbed into the fibre. Physically, wicking is the spontaneous flow of a liquid in a porous substrate, driven by capillary forces. The type of flow in any porous medium, caused by capillary action, is governed by the properties of the liquid, liquid-medium surface interactions, and geometric configurations of the pore structure in the medium $[13,23]$. The rate (distance per unit of time) of liquid which travels along and through a fabric specimen is visually observed according to a standardised wicking method, and manually timed and recorded at specific intervals. There are many alternative wicking test methods. Perwuelz et al. [21] used an image analysis method to investigate the capillary rise of coloured liquid in yarns structure. Another method deals with measuring water transport along textile fibres by an electrical capacitance that consists of the construction of an apparatus with a specially designed electrical amplifier circuit and condenser electrodes, between which sample fibres are placed $[7,26]$. Furthermore, there exist wicking methods based 
on electrical resistance $[16,1]$. The moisture management tester (MMT) is a sophisticated test equipment that evaluates absorption properties of fabric and suitably complements standardised vertical or horizontal wicking testers. This method uses measuring changes in electrical conductivity of tested materials in order to optimise liquid transport properties of fabrics. MMT investigates horizontally dynamic spreading of liquid drops on the surface of samples and in addition evaluates liquid transfer from the fabric's inner surface to its outer surface $[6,20]$. MMT's disadvantage consists in the impossibility to determinate the real spreading direction of liquid moisture. To remove this disadvantage, researches use an image analysis system to capture both area and real spreading direction of liquid (drops of liquid) in horizontal wetting [14, 15,] and vertical wicking [9]. The colour of tested fabrics can influence the accuracy of test results obtained by image analysis, in particular in case of little contrast between the wetted area of a sample and the rest of a sample (the dry area without a drop of water). Consequently, further research was necessary to be realised in order to eliminate these drawbacks.

In the present work a technique based on the combination of thermography system and image analysis system was developed for the evaluation of both vertical wicking of fabrics and horizontal wetting of fabrics. Thermography system takes the advantage of a physical rule: during water evaporation heat arises. This process is possible to be captured on a thermograph by a thermography system. Obtained thermographs are evaluated by an image analysis system to find moisture management parameters of textile materials.

Porosity of textile materials is one of the most important parameters that affect a moisture management of textiles. Obtained 3D structure image of fabric and parameters of 3D porosity by microtomography system allow more detailed view of the causes of material behaviour caused by the spreading of liquid moisture management [24, 25, 3]. For this experiment a nondestructive method of computer microtomography was selected from the existing detection methods of porosity parameters.

The present study is focused on the application of sophisticated textile metrology methods such as thermography and microtomography in order to examine the influence of knit patterns on sweat transport.

\section{Experimental}

\subsection{Materials}

Three groups of knitted fabrics (see Table 1) were analysed in terms of their efficiency of spreading water drops on the surface of knitted samples and vertical wicking behaviour. These materials were designed for patients with skin conditions (e.g. atopic dermatitis, psoriasis) and patients suffering from rheumatic diseases and diabetes. Thermal insulation is a primary feature of the studied materials containing PCM (phasechange material). Moisture management of tested materials is one of other properties that can influence total wearing comfort in case thermal properties are similar. Knitted fabrics are made of the same raw material and the same yarn count; however, all knits have different patterns.

Before being measured, the samples had been washed and air-conditioned for 24 hours. The measurement was carried out in an air-conditioned room under constant conditions at a relative humidity of $65 \%$ and the temperature of $21^{\circ} \mathrm{C}$.

\subsection{Methods}

The liquid moisture transport of knitted fabrics was investigated by four ways:

(i) dynamic liquid transport properties of samples by MMT Moisture Management Tester

(ii) dynamic spreading of liquid drops on the surface of samples by combination of two thermography systems and the image analysis system

(iii) new vertical wicking method which combines the thermography system and the image analysis system

(iv) 3D porosity of knitted fabric by the microtomography system

The results of the above-mentioned methods were compared and discussed in order to detect the real behaviour of tested knits during liquid transport within their structure. Final values (means) of all tested parameters correspond to ten measurements on average.

Table 1. Characteristics of tested knitted fabrics

\begin{tabular}{|c|c|c|c|c|c|c|}
\hline \multicolumn{2}{|r|}{ Fabric } & Pattern & Yarn & $\begin{array}{c}\text { Density } \\
\text { [courses x wales/ }\end{array}$ & $\begin{array}{c}\text { Weight } \\
{\left[\mathrm{g} / \mathrm{m}^{2}\right]}\end{array}$ & $\begin{array}{l}\text { Thickness } \\
{[\mathrm{mm}]}\end{array}$ \\
\hline A & \multirow{3}{*}{$\begin{array}{l}50 \% \text { Cotton / } 30 \% \text { SmartCel } \\
\text { Senzitive (lyocell containing } \\
\text { PCM) / } 20 \% \text { SeaCell pure } \\
\text { (lyocell containing seaweed) }\end{array}$} & interlock & 20 & $170 \times 150$ & 182 & 1.08 \\
\hline B & & $\begin{array}{l}\text { piqué - single } \\
\text { jersey }\end{array}$ & 20 & $140 \times 120$ & 153 & 0.84 \\
\hline C & & plain jersey fabric & 20 & $180 \times 150$ & 131 & 0.69 \\
\hline
\end{tabular}




\section{Moisture Management Tester}

The MMT was developed to quantify dynamic liquid transport properties of knitted and woven fabrics through three dimensions:

- absorption rate - moisture absorbing time of the fabric's face and back surfaces

- one-way transportation capability - one-way transfer from the fabric's back surface to its face surface

- spreading/drying rate - the speed at which liquid moisture spreads across the fabric's back and face surfaces.

MMT consists of upper and lower concentric moisture sensors. The specimen is held flat under a fixed pressure between the sensors while standard test solution is introduced to the back surface of the fabric. Electrical resistance changes between the upper and lower sensors which are then recorded dynamically. Based on the electrical resistance changes, several parameters are determined. These parameters are described in detail in Hu's work and other research [6, 27]. Two parameters were analysed in this study: OMMC [-] - overall moisture management capacity and OWTC [-] - cumulative one-way transport capacity.

OMMC is an index which indicates the overall ability of the fabric to manage the transport of liquid moisture, which includes three aspects of performance: the moisture absorption rate of the face side, one-way liquid transport ability, and moisture drying speed of the face side, which is represented by the maximum spreading speed. [6]

OWTC is defined as the difference in the cumulative moisture content between the two surfaces of the fabric. [6] Negative values mean that the cumulative moisture content on the back surface of the fabric is higher than on the face surface.

\section{Dynamic spreading of a liquid drop on a sample surface by thermography systems}

This part introduces a new experiment within the scope of which areas where liquid moisture spreads are observed by a thermography camera. Figure 1 represents the schema of the aforementioned method. Two thermography systems (FLIR SC6540, ThermaCAM S60) are video-recorded simultaneously by the spreading of a liquid drop (that simulates perspiration) on the surface of a textile sample both on the back and face of the fabric after the application of the liquid. Drops were applied by means of the FB32266 digital micropipette with a volume of $20 \mu \mathrm{l}$. Emissivity of tested fabrics was set to 0.86 .

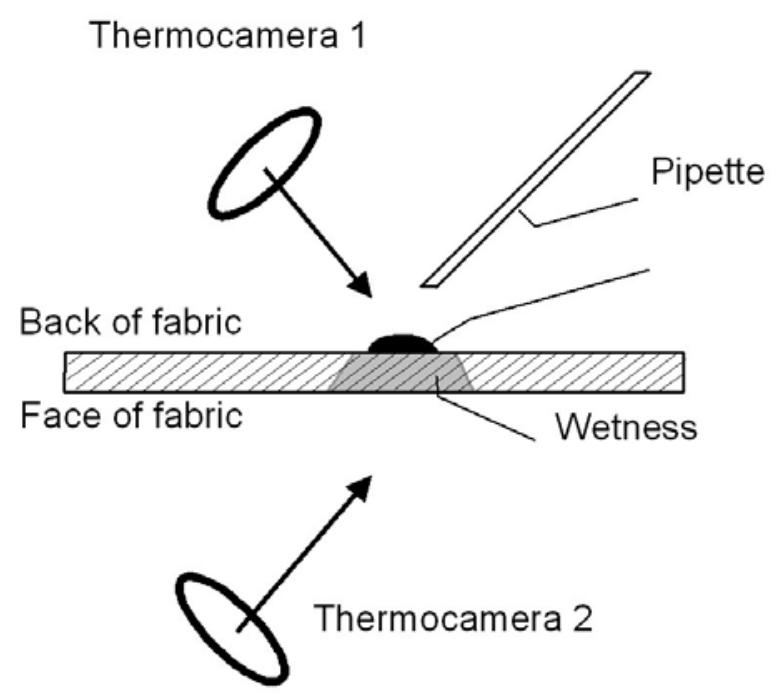

Figure 1. Schema of the testing method

The experiment allows monitoring how fast a material is able to absorb the liquid and the transmission of the moisture from the back to the face of the fabric in real time. The following analysis of recorded thermographs by image analysis system (NIS Element), see figure 2., enables to evaluate the real spreading direction of liquid moisture and the real shape of the area wetted by a drop of water.

The use of infrared cameras for monitoring the spread of liquid in the fabric is possible thanks to the visibility of physical phenomena in infrared spectrum wavelengths. Based on the principles of electromagnetic wave motion, a thermography camera is used in order to represent material characteristics in infra-red wavelengths.

The experiment took place in a measurement dark chamber with dimensions of $130 \times 100 \times 155 \mathrm{~cm}$. All processes were automated in order to eliminate external environment influences and to ensure stable conditions. Detailed information about the principle of the aforementioned method is described in Nemcokova's work [18].

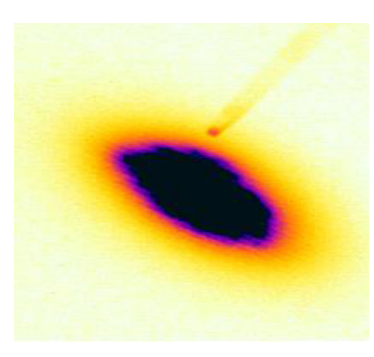

a

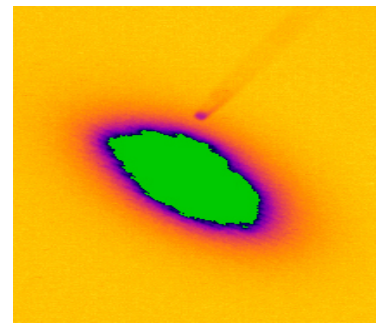

b

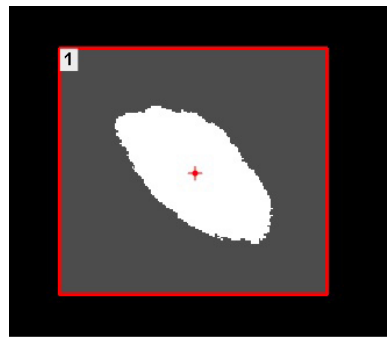

C

Figure 2. The original thermograph image - distribution of the liquid (a), selected area of interest (b), prepared binary image for image analysis (c) 
The following parameters were evaluated in images by image analysis system:

- wetted area $A\left[\mathrm{~mm}^{2}\right]$ at wetting time $180 \mathrm{sec}$.

- equivalent diameter $\mathrm{De}[\mathrm{mm}]$,

$$
D_{e}=\sqrt{\frac{4 A}{\pi}}
$$

- MaxFeret Fmax [mm], MinFeret Fmin [mm]. This feature is the maximal (minimal) value of the set of Feret's diameters. Feret's diameter at angle $\alpha$ equals the projected length of object at angle $\alpha, \alpha(0,180)$; NIS-Elements AR calculates Feret's diameter for $\alpha=0,10,20,30, \ldots, 180$.

- Elongation $E[-]$ is determined as a ratio of MaxFeret and MinFeret features. This feature is useful for shape characteristics, see figure 2 an equation 2 ,

$$
E=\frac{F_{\max }}{F_{\min }}
$$

- orientation $O[\mathrm{~mm}]$, is the angle at which Feret's diameters have their maximum,
- circularity $C[-]$ that is useful for examining shape characteristics. Circularity equals to 1 only for circles; all other shapes are characterized by circularity smaller than 1 . It is a derived shape measure, calculated from the area and perimeter.

$$
C=\frac{4 \pi A}{R^{2}}
$$

\section{Vertical wicking method by thermography system}

The rate of water transport is measured according to a vertical strip wicking test. One end of a fabric strip is secured vertically while the opposite end dangles in a dish containing distilled water. The height to which the water was transported along the strip is measured at intervals of 1,5 , and 10 minutes, and reported in millimetres $(\mathrm{mm})$. Higher wicking values show greater capability for transporting liquid water. Thermal imaging is used to monitor moisture transport when wicking cannot be easily detected with the naked eye. Obtained thermograms are evaluated by image analysis system to find moisture management parameters of textile materials (see Figure 4). Figure 3 represents schema of the used method.

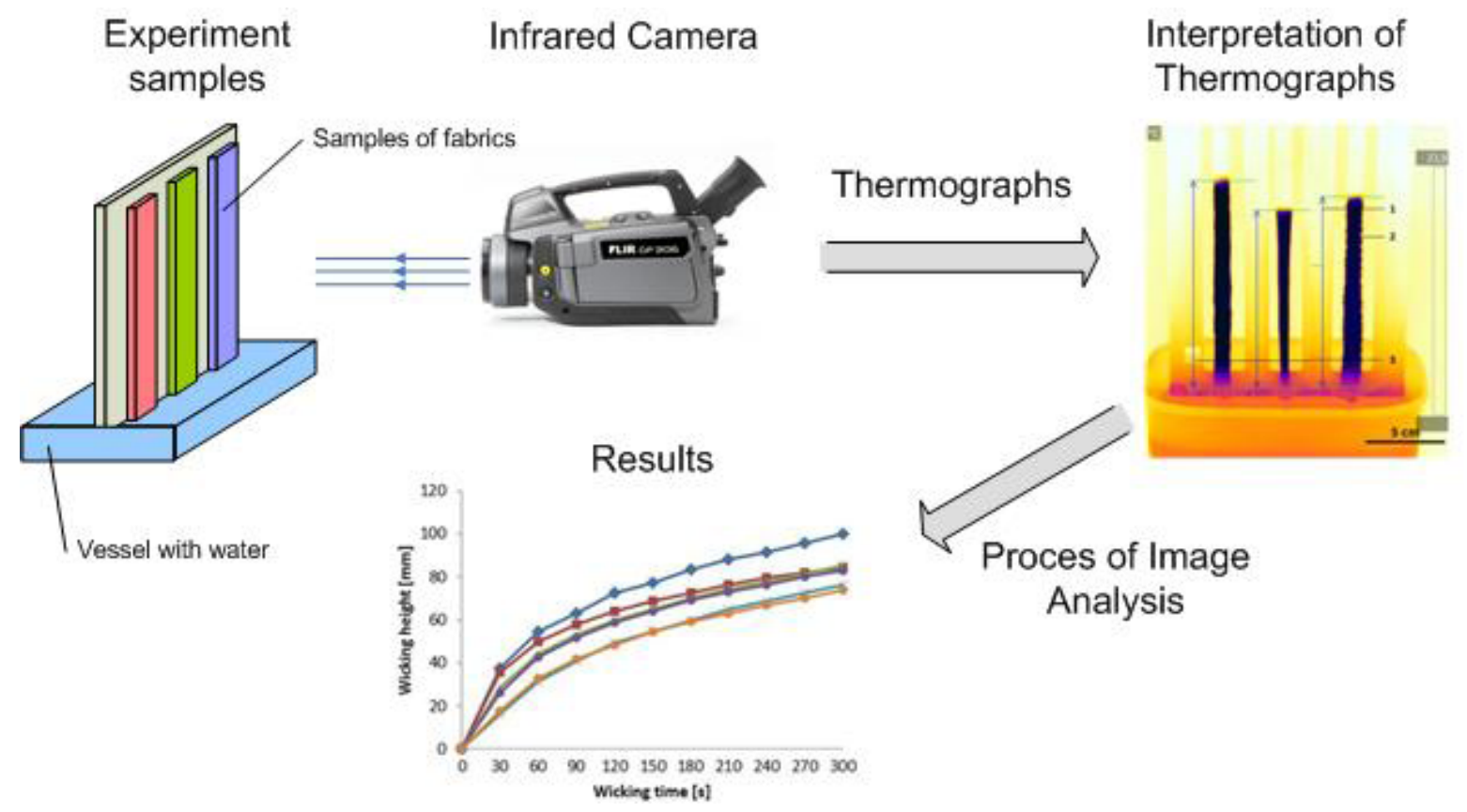

Figure 3. Schema of evaluation of vertical wicking by thermography system

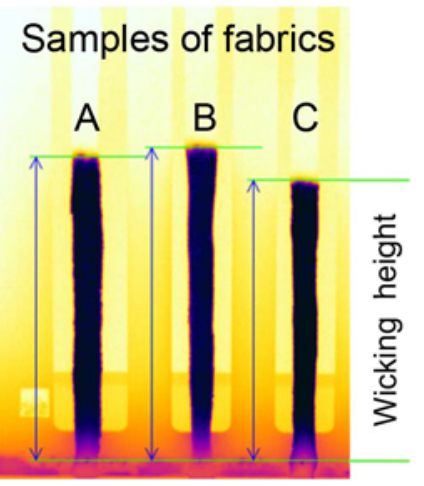

Figure 4.Vertical wicking assessed via thermography system. 


\section{D porosity of knitted fabrics by a microtomography system}

Textile porosity is a key parameter which affects its permeability such as air and watervapour permeability, water transportin liquid form, thermal resistance, etc. X-ray computed microtomography system SKYSCAN 1272 was used to investigate the influence of fabric porosity on the efficiency of liquid transport of textile structures. The method of finding values of flow permeability of porous materials, based on numerically solving fluid flow through the actual 3D pore geometry of material samples found using X-ray microtomography, appears useful especially in cases where experimental results are not available or difficult to obtain [12]. Industrial tomographs offered on the market mostly have a similar construction. Between the X-ray source and the detector (see Figure 5), which converts radiation into an electrical signal (the information), the measured specimen rotates about a vertical axis. During this rotation 2D images (slices) are taken in many steps. From these (often hundreds of) images, reconstruction software creates a $3 \mathrm{D}$ model of the real specimen in the form of cloud points ( see illustrational image in figure 6). These points called voxels (derived from the concept of spatial point - volume pixel) are points ordered in space that are associated with information about the absorption properties of the real object in this position [10].

Measurements were taken under the following settings: image pixel size $-10,7 \mu \mathrm{m}$, rotation step $-0.2^{\circ}$, rotation degrees - $180^{\circ}$, frame averaging -3 , exposure $-900 \mathrm{~ms}$, voltage source - $50 \mathrm{kV}$. These conditions appeared as the best from both points of view, improved scanning speed and the quality of the scanned image. The above-mentioned conditions are common for all tested materials.

The parameters porosity [\%], percent volume in range of pores [\%], and connectivity [-] were established. Connectivity is defined as the maximal number of branches that may be cut without separating the structure. Connectivity can easily be calculated from a 3D data set by using the Euler number. As pointed out, the edge problem needs special attention in all quantifications of connection and adjustment of the Euler number might be necessary [19].

\section{Results and discussion}

\subsection{Dynamic liquid transport properties of sample by Moisture Management Tester}

Two parameters which were analysed in this study OMMC (overall moisture management capacity and OWTC (cumulative one-way transport capacity) are described in Figures $7,8$. Graph OWTC shows negative values which demonstrate that water content of fabric's face surface is lower than that of its back one. This indicates that the liquid introduced onto the back surface of the fabric transfers to the face surface not so

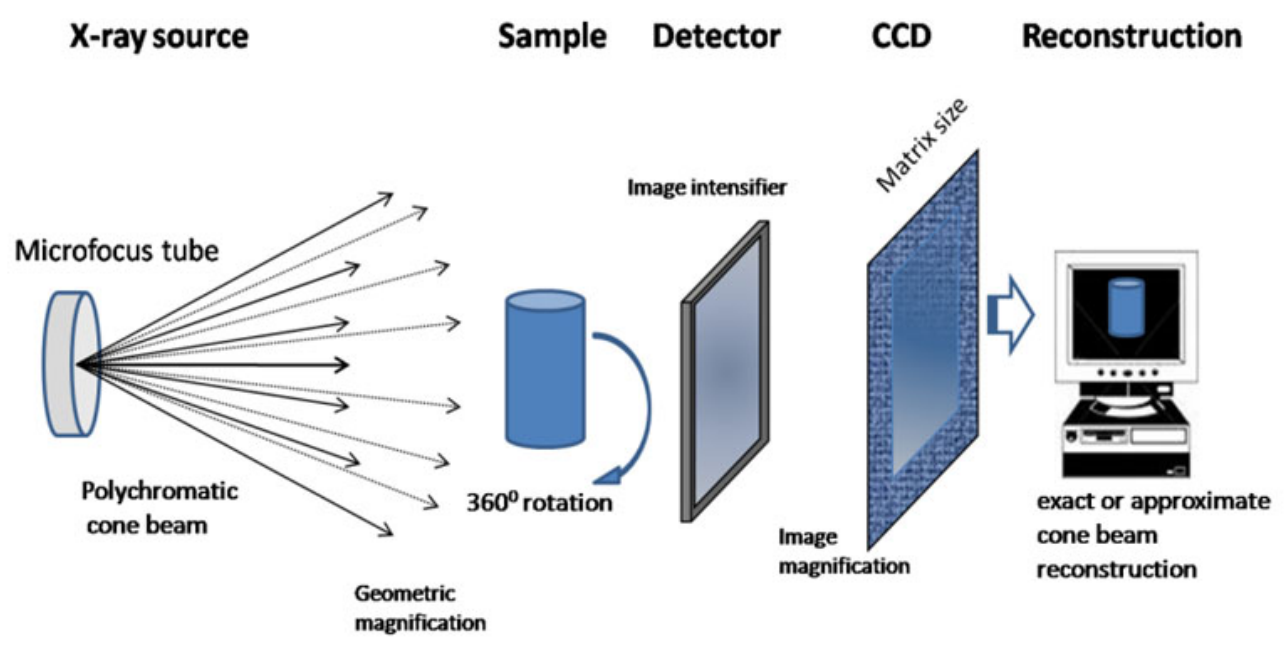

Figure 5. Schema of basic principle of microtomography [22]

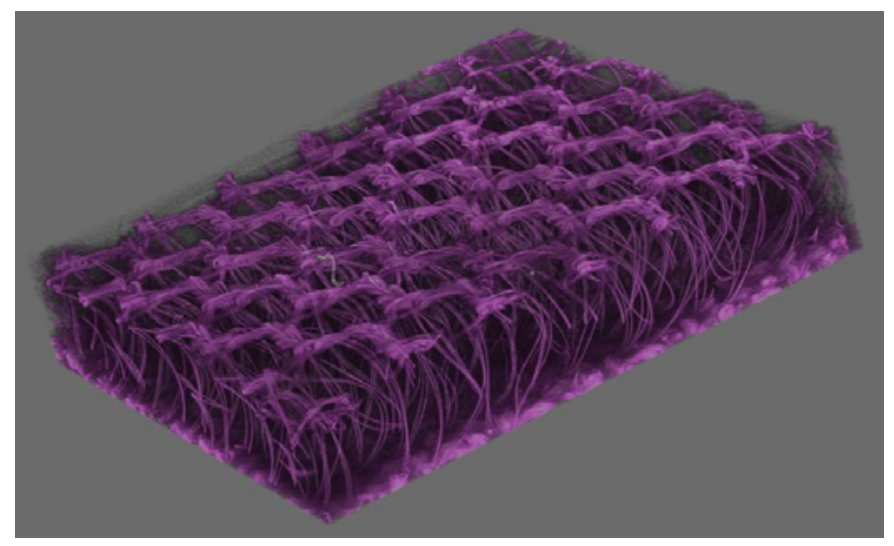

Figure 6. 3D structure image of spacer fabric A by SKYSCAN 1272 
fast. One-way transport capacity is poor or fair for all samples. The larger the negative value, the worse the transfer fluid. Best value shows the tested material $A$.

Graph OMMC indicates very small differences between all three samples that come under the category of slow absorbing and slow drying fabrics with slow spreading and poor one-way transport of liquid.

Complex analysis of all dynamic liquid transport properties is necessary in this case, because final OMMC parameter shows very similar values without bigger differences. Individual parameters such as OWTC and max wetted radius give detailed results.

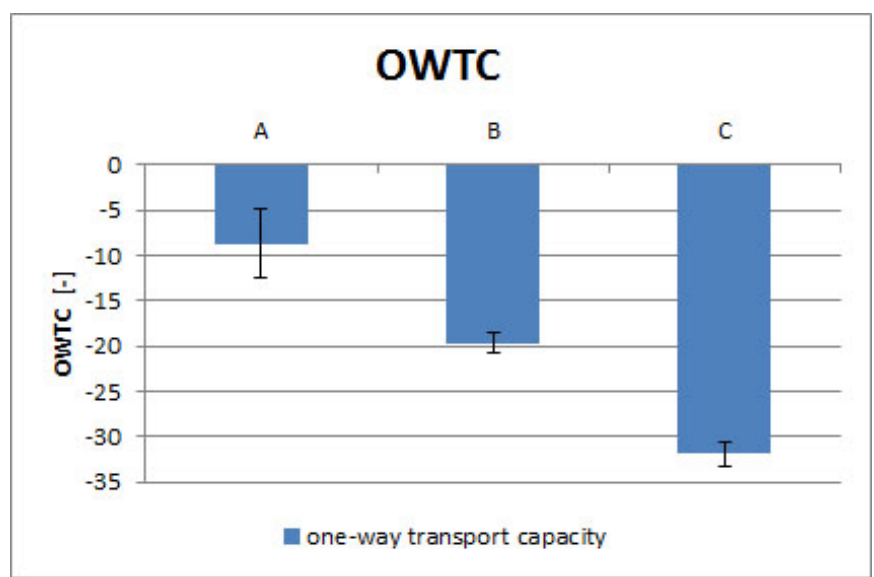

Figure 7. Results of cumulative one-way transport capacity (OWTC) of tested materials measured by MMTI

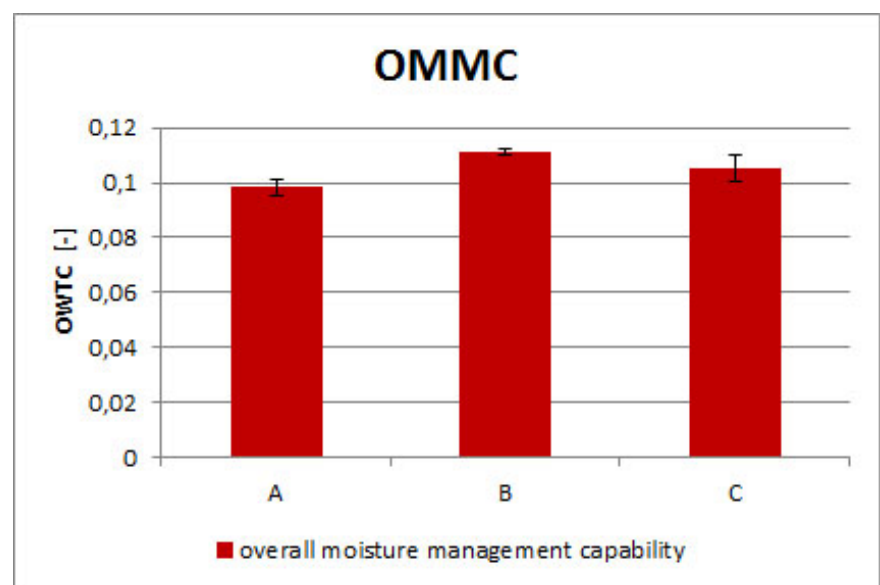

Figure 8: Results of overall moisture management capability (OMMC) of tested materials measured by MMT

\subsection{Dynamic spreading of a sweat drop on the surface of a sample by thermography}

Thermograph records of the measurements were evaluated using the ThermaCAM Researcher Professional program. Calculation of the size of the measured area was determined by means of the NIS - elements image analysis system (see Figure 2). The measured values show average area values $\left(\mathrm{mm}^{2}\right)$ of three measurements of a particular material. The wetting process is manifested by various liquid moisture spread speeds and sizes of the wetted area, depending on the pattern of knitted fabric. The following figure (Figure 9) includes an evaluation of the spread of liquid moisture in time 180 seconds, for the back and face of fabrics.

The results of wetting the fabric on the back may indicate how fast the fabric is able to absorb and spread liquid moisture on its surface. Wetting speed is an essential criterion in selection of materials for the given purpose. By observing the behaviour of the spread of liquid onto the outside of the fabric, we will get much more important results; since liquid transmission through the material is obviously one of the conditions to label a material as suitable for functional clothes. There are only results of spreading moisture because of comparison with the above method MMT. The speed of spreading moisture is not listed, but this is possible to monitor and evaluate [18].

What we want is transmission of perspiration from the back to the face of the fabric because it is important for draining off perspiration from the skin. The ratio of the measured areas may reflect the dynamics of the liquid moisture transmission. Although the proposed method and MMT method don't evaluate the same measurement parameters, we can say that the trends of the results are similar ( see Figure 10). No knitted fabric exhibits a good moisture transfer. From the results of knitted fabric $A$, it can be assumed that the liquid moisture is contained in the internal structure (between back and face surfaces) of the knit, which is due to its thickness. The influence of the knitted fabric pattern on the wetting process is evident.

Selected measured features are useful for shape characteristics of the wetted area. The results of image analysis measurements in form of the shape characteristics give the possibility to discuss the shape of the wetted surface.

Circularity for all tested materials that results from thermography measurements shall not take the values 1 , which is determining the circular shape. This is in contrast with the MMT method

Table 2. Other parameters of MMT evaluation

\begin{tabular}{|c|c|c|c|}
\hline Fabric & $\begin{array}{c}\text { One - way } \\
\text { transport index } \\
(\mathbf{1 - 5})\end{array}$ & $\begin{array}{c}\text { Overall } \\
\text { moisture } \\
\text { management } \\
(\mathbf{1 - 5 )}\end{array}$ & $\begin{array}{c}\text { Max wetted radius Rmax } \\
\text { Top surface (back of fabric) / Bottom surface (face of } \\
\text { fabric) } \\
\mathbf{( 0 - 2 5 )}\end{array}$ \\
\hline A & 2 & 1 & $12.5 / 10$ \\
\hline B & 1.5 & 1 & $15 / 10$ \\
\hline C & 15 & 1 & $13.3 / 10$ \\
\hline
\end{tabular}




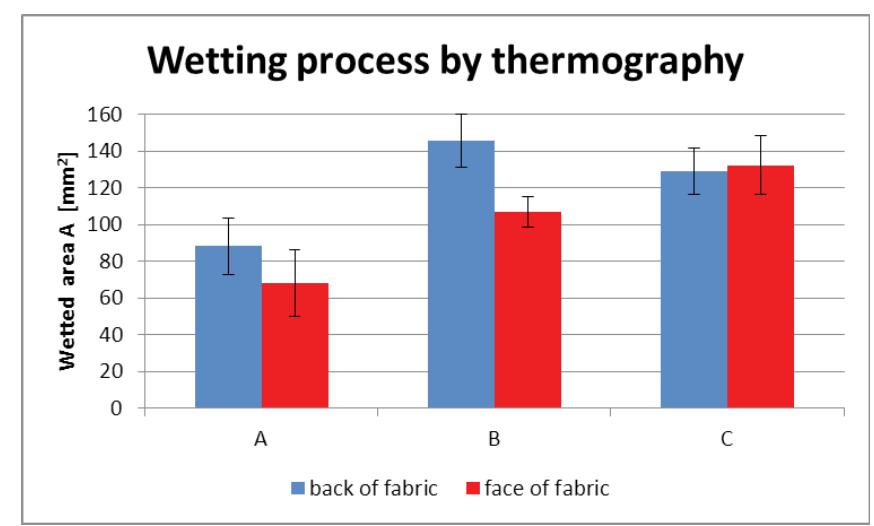

Figure 9. Results of wetted area measured by thermography method

which is - on the contrary - based on the detection of moisture circular shape.

Orientation parameter indicates that the dominant direction of moisture distribution measured for all samples was in the wale direction. Different values for the face and back surfaces are caused by the particular different location of thermal cameras. However, the final angles of the dominant direction of moisture distribution are similar. See Figure 1.

\subsection{Vertical wicking method by a thermography system}

The wale and course wicking height of three samples in 600 seconds can be seen in Figure 11 and the graph of the wickability to 300 seconds is plotted against time in Figure 12.

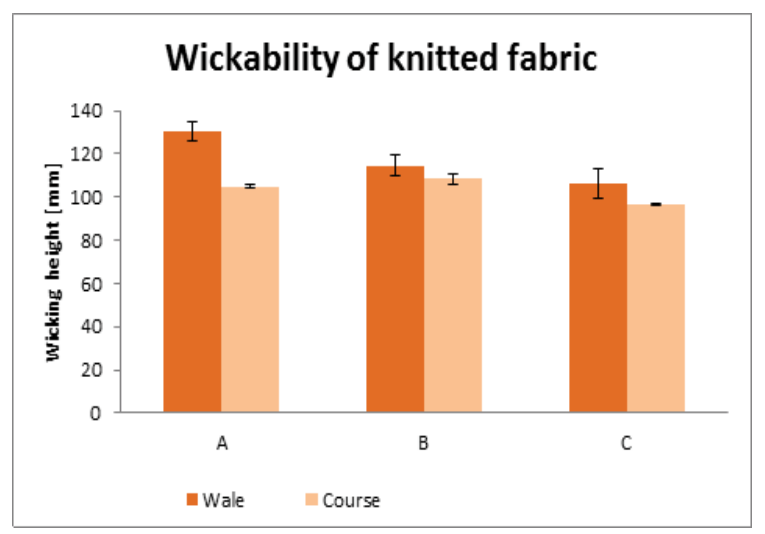

Figure 11. Effect of fabric structure on vertical wickability in time 600 seconds

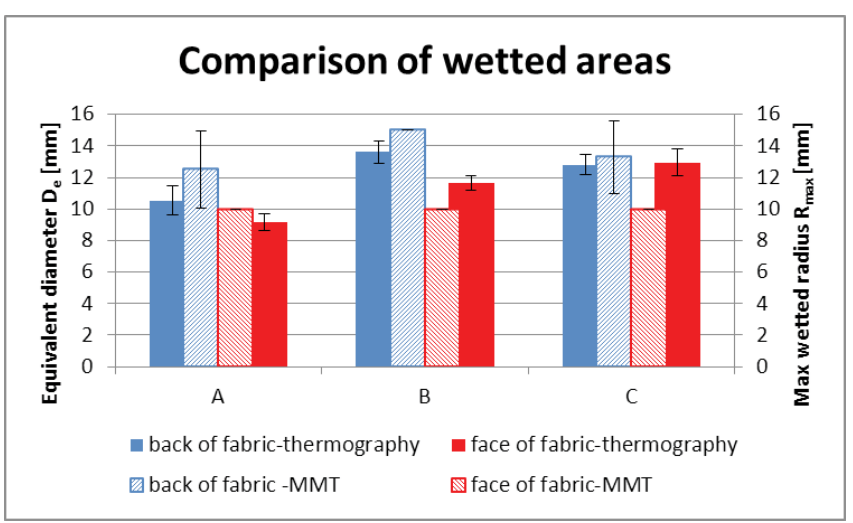

Figure 10. Comparison of the spreading of the liquid moisture transmission by thermography system and MMT method

In time interval from 0 to 300 seconds the graph shows the most important progress. The initial wicking rate, which is the tangent slope at the initial time and the ultimate wicking height at 600 seconds, is also listed in Table 4. All the results are based on the average numbers of ten executed tests.

As it can be seen, the total transport of liquid moisture in a fabric is performed in two stages. The first stage of liquid absorbing capability is expressed as an initial wicking rate, and the second stage as ultimate wicking height. The experimental results show that a interlock (knit A) performed better instant water absorbing capability varying from $0.87 \mathrm{~mm} / \mathrm{s}$ to 1.26 $\mathrm{mm} / \mathrm{s}$ and water transporting abilities varying from $104.9 \mathrm{~mm}$ to $130.7 \mathrm{~mm}$. But a plain jersey performed instant water absorbing capability from $0.54 \mathrm{~mm} / \mathrm{s}$ to $0.59 \mathrm{~mm} / \mathrm{s}$ and wicking height

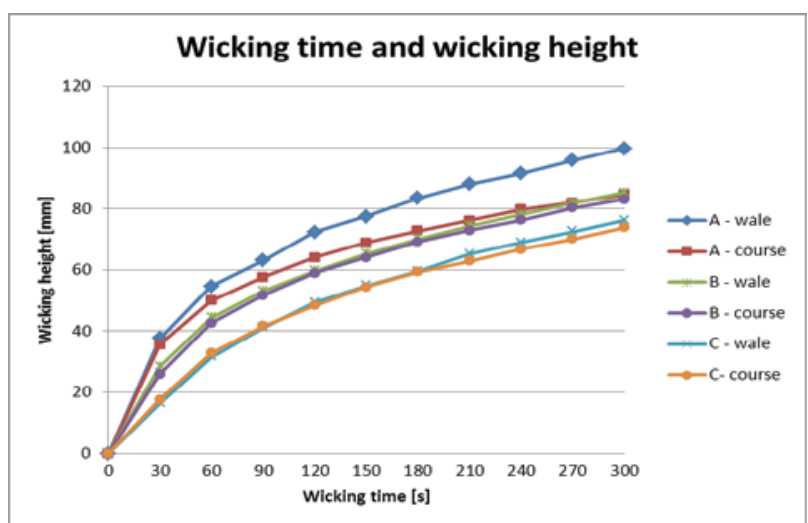

Figure 12. Wicking height and time curve in 300 seconds

Table 3. The selected parameters of shape characteristics

\begin{tabular}{|c|c|c|c|c|c|c|c|c|c|c|c|c|c|}
\hline \multicolumn{2}{|c|}{$\begin{array}{c}\text { Back of } \\
\text { fabric }\end{array}$} & \multirow{2}{*}{$\begin{array}{l}\text { Fmax } \\
\text { [mm] }\end{array}$} & \multirow{2}{*}{$\begin{array}{l}\text { Fmin } \\
{[\mathrm{mm}]}\end{array}$} & \multirow{2}{*}{$\begin{array}{c}\text { C } \\
{[-]}\end{array}$} & \multirow{2}{*}{$\begin{array}{c}\mathbf{E} \\
{[-]} \\
1.64\end{array}$} & \multirow{2}{*}{$\begin{array}{c}\begin{array}{c}\text { O } \\
\text { [deg.] }\end{array} \\
150.33\end{array}$} & \multicolumn{2}{|c|}{$\begin{array}{c}\text { Face of } \\
\text { fabric }\end{array}$} & \multirow{2}{*}{$\begin{array}{l}\begin{array}{c}\text { Fmax } \\
\text { [mm] }\end{array} \\
12.28\end{array}$} & \multirow{2}{*}{$\begin{array}{c}\begin{array}{c}\text { Fmin } \\
{[\mathrm{mm}]}\end{array} \\
9.24\end{array}$} & \multirow{2}{*}{$\begin{array}{c}\text { C } \\
{[-]} \\
0.48\end{array}$} & \multirow{2}{*}{$\begin{array}{c}\mathbf{E} \\
{[-]}\end{array}$} & \multirow{2}{*}{$\begin{array}{c}\begin{array}{c}\text { O } \\
\text { [deg.] }\end{array} \\
87.17\end{array}$} \\
\hline A & mean & & & & & & & mean & & & & & \\
\hline$\pi$ & st.dev. & 1.91 & 1.26 & 0.08 & 0.19 & 4.96 & & st.dev. & 2.03 & 1.70 & 0.12 & 0.23 & 10.82 \\
\hline \multirow{2}{*}{ B } & mean & 17.66 & 16.17 & 0.80 & 1.10 & 148.25 & \multirow{2}{*}{ B } & an & 14.05 & 12.85 & 0.47 & 1.09 & 85.75 \\
\hline & st.dev. & 1.91 & 1.38 & 0.02 & 0.14 & 6.26 & & st.dev. & 0.69 & 0.23 & 0.10 & 0.04 & 52.83 \\
\hline \multirow{2}{*}{ C } & mean & 19.21 & 12.74 & 0.68 & 1.53 & 147.00 & \multirow{2}{*}{ C } & mean & 16.91 & 13.34 & 0.54 & 1.29 & 89.50 \\
\hline & st.dev. & 1.41 & 1.41 & 0.06 & 0.21 & 6.90 & & st.dev. & 2.02 & 1.72 & 0.07 & 0.21 & 15.69 \\
\hline
\end{tabular}


Table 4. Detailed parameters of wicking evaluation

\begin{tabular}{|c|c|c|c|c|c|}
\hline \multicolumn{2}{|c|}{$\begin{array}{l}\text { Fabric/statistical } \\
\text { characteristics }\end{array}$} & $\begin{array}{l}\text { Initial wicking rate } \\
\text { in wale } \\
(\mathrm{mm} / \mathrm{s})\end{array}$ & $\begin{array}{l}\text { Ultimate wicking } \\
\text { height in wale } \\
\text { (mm) }\end{array}$ & $\begin{array}{l}\text { Initial wicking rate } \\
\text { in course } \\
(\mathrm{mm} / \mathrm{s})\end{array}$ & $\begin{array}{l}\text { Ultimate wicking } \\
\text { height in course } \\
(\mathrm{mm})\end{array}$ \\
\hline \multirow{2}{*}{$A$} & mean & 1.26 & 130.70 & 1.19 & 104.90 \\
\hline & st.deviation & 0.11 & 3.90 & 0.08 & 0.83 \\
\hline \multirow{2}{*}{$\mathrm{B}$} & mean & 0.95 & 114.60 & 0.87 & 108.30 \\
\hline & st. deviation & 0.04 & 4.51 & 0.03 & 2.30 \\
\hline \multirow{2}{*}{ C } & mean & 0.54 & 106.40 & 0.59 & 96.70 \\
\hline & st. deviation & 0.05 & 5.89 & 0.05 & 0.54 \\
\hline
\end{tabular}

from $96.7 \mathrm{~mm}$ to $106.4 \mathrm{~mm}$. Water transport in wale and course shows differences which were caused by different patterns of knit fabrics. In general, the wickability of wale is better than the wickability of course from measured samples A, B and C.

Textiles fabrics contain imperfect capillaries, with no other properties than gross surface characteristics, such as the troughs on the surface of the interlock knit, universally contributing to their wicking behaviour. Therefore, the wicking behaviour of each fabric must be determined individually.

\subsection{Porosity of knitted fabric by microtomography system}

First, the structures of knits were scanned by means of microtomography system SkyScan 1272. Second, the 3D reconstructions of scanned images were carried out by software NRecon and subsequently parameters of $3 \mathrm{D}$ porosity were determined by software CTAn for tested materials. Figures 13, 14 and 15 show final 3D images of tested materials from front and isometric views. These images represent the area of tested knits size $5 \times 5 \mathrm{~mm}$. There are detailed views to knits structure in the images.

Knitted fabric A shows the similar value of porosity to material B approximately $57 \%$ (open porosity was $56 \%$ from that value) material $C$ proves less porosity than $A$ or $B$, see figure 16. Nevertheless, material $A$ is the best one considering the liquid transport results of performed tests such as wicking test, MMT, etc. It can be caused by both different sizes (diameters) of pores which participate in capillary transport phenomena and surface tension between the fabrics and water. For this reason, the structure separation distribution of pores into tested materials was investigated for both material $A$ and material $B$ in this study. There is percent volume in the range
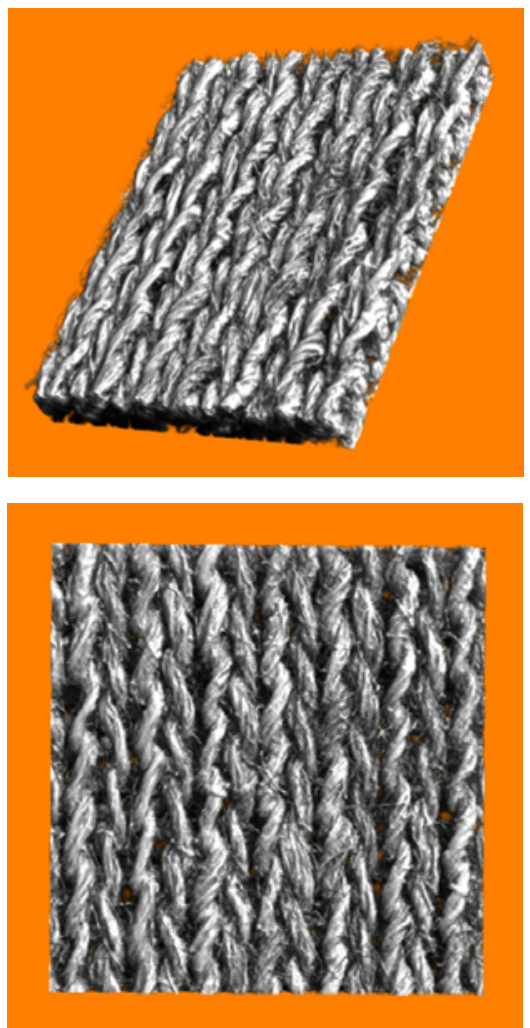

Figure 13. a, b. Demonstration 3D images of knit $\mathrm{A}$ by microtomography system SkyScan 1272
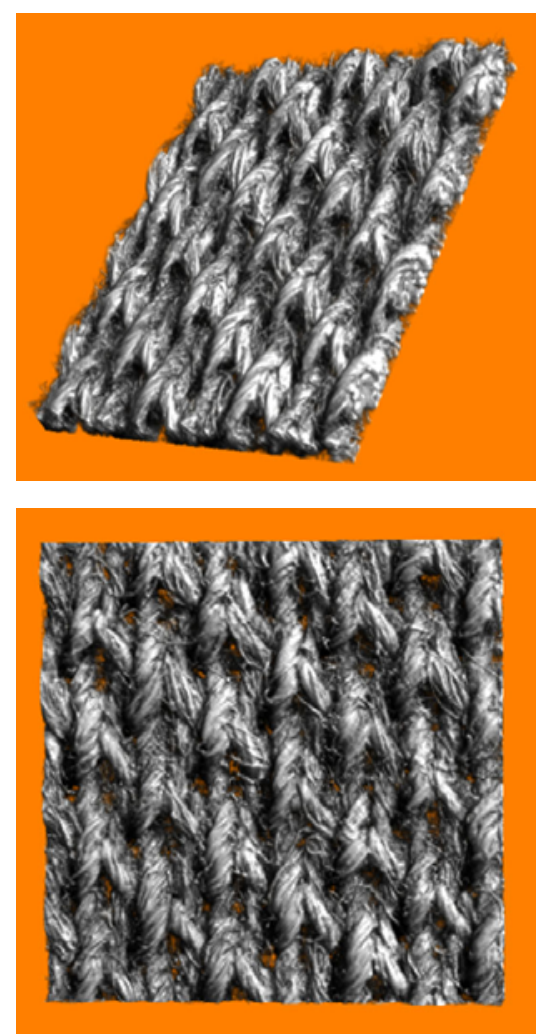

Figure 14. a, b. Demonstration 3D images of knit $B$ by microtomography system SkyScan 1272
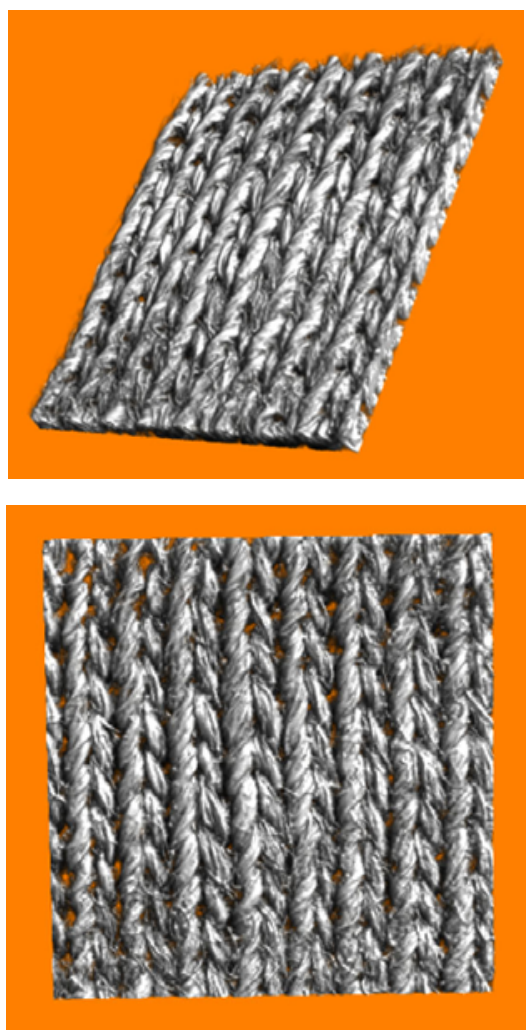

Figure 15. a, b. Demonstration 3D images of knit $\mathrm{C}$ by microtomography system SkyScan 1272 

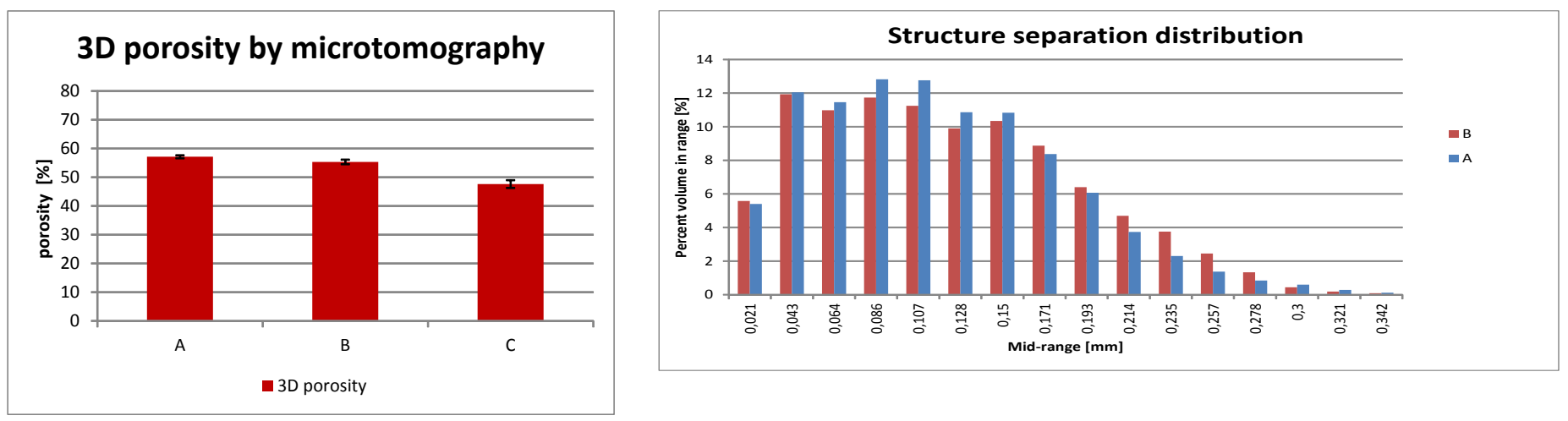

Figure 16. Porosity of tested fabrics by microtomography Figure 17. Structure separation distribution of pores by CTAn. system SKYSCAN 1272

of pores [\%] against to mid-range [mm] of pores in figure 17. Figure 17 shows that knitted fabric A contains more pores in range from $64 \mathrm{~mm}$ to $150 \mathrm{~mm}$ than knitted fabric $B$. Further, fabric $B$ has more pores in range from $235 \mathrm{~mm}$ to $280 \mathrm{~mm}$. Fabric $A$ is better due to aforementioned distribution of pores. Moreover parameter connectivity of fabric $A$ shows twice higher value (about 49,000 ) than connectivity value of fabric $B$ (about $21,000)$. As our research has shown, the distribution of pores in fabrics and pore diametres is very important parameters to uncover liquid transport behaviour of textile structures.

\section{CONCLUSION}

Several experimental methods have been proposed for the measurement of liquid transfer behaviour of textiles up to the present. The results of this investigation show that each of these methods brings some advantages, but on the other hand there are some drawbacks too, for example, a bad contrast between wet and dry areas of samples caused by the colour of tested fabrics (classical vertical wicking test), incomplete information about the direction of spreading drop on textile surface (MMT), etc. To uncover the efficiency of moisture management of textiles from a comprehensive view, the dynamic moisture transport of knitted fabrics was investigated by advanced methods, such as thermography and microtomography systems in this study. These applied alternative methods appropriately complement standardised ways of liquid transport evaluation and make them more precise; in particular in the cases when fabrics objective show similar comfort properties, but a wearer's personal experience is different (worst, better).

There were three groups of knitted fabrics compared with each other in order to determine the influence of knitted patterns on sweat transport by the proposed methods. In addition to commonly measured parameters of vertical wicking and horizontal wetting (wicking height, speed of wicking, wetting area, etc.), some additional features were measured, such as equivalent diameter, orientation, circularity, elongation, 3D porosity, etc.

If solely MMT test and vertical wicking test are used, we find that material $A$ is the best (on the basis of OMMC, OWTC, wicking speed or height, etc.). Further, it can be concluded that dynamic spreading of liquid drop test by thermography system has confirmed the trend of ratio of maximal wetted areas between back and face surface means of MMT test. This method is therefore appropriate for diametric differences in structure and in material parameters (hydrophilic/hydrophobic). Moreover, this method could determine the direction of spreading of liquid drops on the surface of samples and other characteristics which describe the shape of the wetted face and back areas of knits.

It is possible to use the parameter of $3 D$ porosity for rough estimation of fabrics' transport properties of liquids, but the determination of pores distribution in fabrics by structure separation distribution of pores (in CT An) can be helpful in order to uncover the real reason of transport behaviour of liquids of textile structures.

\section{ACKNOWLEDGEMENTS}

This research work was supported by Technology Agency of the Czech Republic Project No. TA01011253.

\section{References}

[1] Babu, R., (2012). Analysis of Fabrics Structure on the Character of Wicking, Journal of Engineered Fibers and Fabrics, 7 (3), 28-33

[2] Bao-guo, Y., et al., (2006). An Improved Test Method for Characterizing the dynamic liquid moisture transfer in porous polymeric materials. Polymer Testing, 25 (5), 677689

[3] Doczyova, K., Glombikova, V., Komarkova, P., (2014). Application of Microtomography in Textile Metrology, Tekstilec, 57 (1), 4-11

[4] Ho, C.P, et al., (2011). Improving Comfort in Apparel, Woodhead Publishing Limited, Cambridge, UK, Improving thermal comfort in apparel, ISBN 978-1-84569-539-2

[5] Hsieh, Y. L., (1995). Liquid Transport in Fabric Structures. Textile Research Journal, 65 (5), 299-307

[6] Hu, J. et al. (2005). Moisture Management tester: A Method to Characterize Fabric Liquid Moisture Management properties, Textile Research Journal, 75 (1), 57-62

[7] Ito, H., Muraoka, Y., (1993). Water Transport Along Textile Fibres as Measured by an Alectrical Capacitance Technique, Textile Research Journal, 63 (7), 414- 420 
[8] Grujic, D. et al., (2014), Impact of Fibre Composition and Sports T-Shirt Ventilation on Thermal Comfort, Tekstilec, 57(3), 220-230

[9] Jiang, X.Y., et al., (2010). Image Processing Techniques and its Application in Water Transport through Fabrics, Journal of Fiber Bioengineering and Informatics, 3 (2), 8893

[10] Katuch, P., Zivcak, J., (2010). Priemyselná tomografia. Nový rozmer v metrológii., [retrieved 06-21-2014]. <http:// www.cttc.sk/podklady/metro2010.pdf>

[11] Kissa, E., (1996). Wetting and Wicking, Textile Research Journal, 66(10), 660 - 668

[12] Koivua, V., et al., (2009). Transport Properties of Heterogeneous Materials. Combining Computerised X-ray Micro-tomography and Direct Numerical Simulations. International Journal of Computational Fluid Dynamics, 23 (10), 713-721

[13] Machova, K., et al., (2006), Air Streaming in Spacer Fabrics to Support the Wear Comfort of Sport and Outdoor Clothing, Melliand, 6, 23-28

[14] Memariyan, F., Ekhtiyari, E., (2010). Study on Wicking Measurement in Thin Layer Textiles by Processing Digital Images, IJE Transactions A: Basics, 23 (1),101-108

[15] Morent, R., et al., (2006). Measuring the Wicking, Behavior of Textiles by the Combination of a Horizontal Wicking Experiment and Image Processing, Review of Scientific Instruments, 77(9), 093502 - 093502-6

[16] Nath, J., et al., (2001). Design and Development of Multipurpose Absorption Rate Meter, Journal of Agricultural Engineering, 38 (2), 134-140.

[17] Nazir, A., et al., (2014). Effect of Knitting Parameters on Moisture Management and Air Permeability of Interlock Fabrics, AUTEX Research Journal, 14(1), 39-46
[18] Nemcokova, R., Komarkova, P., (2014). Experimental Measurement of Liquid Moisture Transmission Through Textiles, Vlakna a textil, 21 (4), 39-47

[19] Odgaard, A., (1997) Three-Dimensional Methods for Quantification of Cancellous Bone Architecture, Bone; Vol. 20, 315-328.

[20] Oner, E., et al., (2013). Evaluation of Moisture Management Properties on knitted fabrics, Journal of the Textile Institute, 104 (7), 699-707

[21] Perwuelz, A., et al., (2000). Experimental Study of Capillary Flow on Yarns, Textile Research Journal, 70 (4), 333-339

[22] Promentilla, B., Michael, A., (2011). Characterizing the Microstructure of Deteriorated Cementitious Materials with $X$-Ray Microtomography, ASEAN Engineering Journal, 1 (4), [retrieved 12-15-2013], http://www.seed-net.org/ ASEANEJ_1-4.html

[23] Rajagopalan, D., et al., (2001). Modeling Capillary Flow in Complex Geometries, Textile Research Journal, 71 (9), 813-821

[24] Ramaswamy, S. et al., (2004). The 3D Structure of Fabric and Its Relationship to Liquid and Vapor Transport, Colloids and Surfaces A: Physicochemical and Engineering Aspects, 241 (1-3), 323-333

[25] Stämpfli, R. et al., (2013). X-Ray Tomographic Investigation of Water Distribution in Textiles Under Compression Possibilities For Data Presentation, Measurement, 46 (3), 1212-1219

[26] Tagaya H., et al., (1987). Measurement of Capillary Rise in Fabrics by Electric Capacitance Method, Sen-i Gakkaishi, 47, $422-430$

[27] Troynikov, O., Wardiningsih, W., (2011). Moisture Management Properties of Wool/Polyester and Wool/ Bamboo Knitted Fabrics for the Sportswear Base Layer, Textile Research Journal, 2011, 81(6), 621-631 